\title{
A comparative environmental impact analysis of asphalt mixtures containing crumb rubber and reclaimed asphalt pavement using life cycle assessment
}

\author{
Sara Bressi ${ }^{\mathrm{a}}$, Joao Santos ${ }^{\mathrm{b}}$, Marko Orešković $\mathbb{1}^{\mathrm{c}}$ and Massimo Losa ${ }^{\mathrm{a}}$ \\ ${ }^{\mathrm{a} D e p a r t m e n t ~ o f ~ C i v i l ~ a n d ~ I n d u s t r i a l ~ E n g i n e e r i n g ~(D I C E), ~ U n i v e r s i t y ~ o f ~ P i s a, ~ P i s a, ~ I t a l y ; ~}{ }^{\mathrm{b}}$ Department of Construction Management \& Engineering, Faculty \\ of Engineering Technology, University of Twente, Enschede, The Netherlands; 'University of Belgrade, Faculty of Civil Engineering, Belgrade, Serbia
}

\begin{abstract}
Recently, the reduction of the environmental burdens related to highway infrastructures has been in the spotlight. Within this context, the use of recycled materials in bituminous mixtures for road pavement construction and maintenance has the potential to mitigate the excessive use of non-renewable resources. Nevertheless, the material consumption is only one of the aspects that affects the sustainability of an infrastructure. Other relevant aspects related to environmental issues should be considered. The objective of this work is to evaluate the potential environmental impacts of asphalt mixtures containing crumb rubber (CR) (vulcanised or devulcanised) and reclaimed asphalt pavement (RAP) assuming different Degree of binder Activation (DoA) of the aged binder by means of a life cycle assessment (LCA). The results show that the small amount of CR used for bituminous mixtures application does not justify all the additional consumption of resources and emissions associated with its treatment. These results are explained by the higher environmental impacts stemming from the treatment of the rubber and the higher amount of bitumen employed in the mixture. In turn, for mixtures containing RAP the analysis revealed an improvement in the score of all the environmental indicators considered.
\end{abstract}

\section{ARTICLE HISTORY}

Received 5 June 2018

Accepted 20 May 2019

\section{KEYWORDS}

Life cycle assessment; crumb rubber; devulcanisation; RAP base course; road sustainable materials

\section{Introduction}

Reclaimed Asphalt Pavement (RAP) and End-of-Life tyres (EOLTs) are among the most popular recycling materials to be used in road construction and maintenance (Silva et al. 2012, Bressi et al. 2016). The massive use of these materials that have the potential to replace non-renewable resources is very attractive because it may lead to the reduction of a set of environmental burdens, such as the greenhouse gas (GHG) emissions and energy consumption (Farina et al. 2017, Wang et al. 2018). In order to provide the reader with some background on the subjects addressed in the paper, the next subsections briefly review the main topics of concern.

\subsection{Vulcanised and devulcanised rubber for dry process in asphalt mixtures}

When $\mathrm{CR}$ is used as a portion of aggregates in a hot mixture asphalt (HMA) in a dry process (FHWA 1997), the resultant product is sometimes referred to as rubber-modified asphalt concrete (RUMAC). This type of mixture usually contains a rubber percentage that varies from $1 \%$ to $3 \%$ by weight of the total aggregate in the mixture and a target air voids content that varies from $2 \%$ to $4 \%$ (FHWA 1997).

To produce tyres, the rubber undergoes a vulcanisation process by using sulfur, peroxides and other substances intended to prevent the tyres from cracking and to improve their properties (Rafique 2012). Therefore, vulcanisation is a process where chemical bonds are created between sulfur and the carbon molecules of rubber. Devulcanisation refers to the process in which the crosslink bonds in the vulcanised rubber are selectively broken, cleaving the sulfur-sulfur or carbon-sulfur bonds and shortening the molecular chains (Rader et al. 1995). Indeed, the three-dimensional network structure restrains the rubber from melting (Fukumori and Matsushita 2003, Mangili et al. 2015). The reclamation of scrap tyres is mainly related to shredding and devulcanisation of $\mathrm{CR}$ (Rafique 2012). The devulcanisation process encompasses several steps that can be summarised as follows: (i) shredding the tyres to small particles of rubber; (ii) fibres and steel removal through the use of suitable separators and (iii) further grinding of the rubber to a finer size and then mixing with different reclaiming agents (Rajan et al. 2006). Shredding is the first stage of the entire process of rubber reclamation and it pulverises the scrap tyres into a fine powder from 10 to 30 mesh (Li et al. 2014).

After shredding, the rubber could be used either directly in a vulcanised state or it can undergo the devulcanisation process. It should be noted that the size of the rubber particles is responsible for the effectiveness of the devulcanisation processes. Certain process requires fine particles, while other can tolerate coarser rubber particles (CalRecovery 2004).

\subsection{RAP mixtures and the Degree of binder Activation}

The re-use and recycling of RAP in the construction and maintenance of infrastructure is a well-known practice that has 
been an object of several research efforts towards maximising the quantity of RAP employed in the production of new asphalt mixtures (Bressi et al. 2016). In this context, the quantification of the Degree Of binder Activation (DoA) defined as the amount of RAP binder that can be considered 'active' in the new formulation of asphalt mixtures incorporating RAP has raised the interest of the scientific community (Shirodkar et al. 2011, Castorena et al. 2016, Cavalli et al. 2016) because the increase of the aged binder mobilised in a new mixture can be seen as a potential way to reduce the consumption of non-renewable resources such as the bitumen.

Quantifying the level of DoA in RAP mixtures is important for mix design purposes because it allows reducing the amount of virgin binder (VB) employed in the mixture (Coffey et al. 2013) and would bring higher level of reliability in the overall process of design, production and compaction of asphalt mixtures containing high quantity of RAP. The fact that a common and standardised procedures are not clearly defined leads to high level of uncertainties associated with the quantification of the DoA, which among other factors, also depends on the characteristics of the RAP and VB (Lo Presti et al. 2019). Therefore, in the framework of this paper several DoAs in an asphalt mixture containing $40 \%$ of RAP were considered to analyse the environmental benefits derived from the reactivation of the aged binder and the reduction of the use of VB.

\subsection{Sustainability assessment of pavements materials}

The majority of the research work addressing the sustainability assessment of road pavement materials aims to compare the potential benefits associated with different solutions, even if that is not the single objective of such analysis (Santero et al. 2011a).

The comparison between different studies applying the Life Cycle Assessment (LCA) methodology is not always possible due to the differences in the functional unit considered, data sources used and geographical and technological contexts associated with the case study. The adoption of different functional units is related to the characteristic of the pavement system under study, which are significantly influenced by the traffic, environmental conditions and design life (Santero et al. 2011a, 2011b, Azarijafari et al. 2016).

Different metrics are used for the evaluation of the environmental performance of the road pavement materials. Among these, the energy consumption and the GHGs emissions are the most popular in the LCA studies (Santero et al. 2011a, Athena Institute 2006, White et al. 2010, Zapata and Gambatese 2005, Santos et al. 2019). Recently, the number and the type of metrics adopted for characterising the environmental performance of asphalt mixtures in Type III Environmental Product Declarations (EPDs) have been standardised by means of Product Category Rules (PCR) (EAPA 2016, The Norwegian EPD Foundation 2010). Although these documents acknowledge the environmental relevance of several materials, such as chemical additives, polymers, ground tire rubber (among others), their exclusion from the system boundaries of the LCA studies behind the EPDs is often recommended on the basis that data is scarce and fragmentary (NAPA, 2017).

In order to fill some of the gaps mentioned above, in this paper different combinations of percentage of rubber and rubber treatments (vulcanised and devulcanised) used in the dry process RUMAC technology for asphalt mixtures are compared in order to evaluate the potential reduction of the environmental burdens arising from the use of these material and technologies in the production of asphalt mixtures.

\section{Objectives and methodology}

A life cycle approach is crucial to identify and quantify the potential environmental benefits derived from the use of alternative materials in asphalt mixtures. This need can be fulfilled with the support of the LCA methodology, which is a data-driven, systematic methodology to estimate the potential environmental burdens caused by a product, process or service throughout its life cycle (Matthews et al. 2015).

The LCA study is performed taking into account as much as possible the ISO 14040 and ISO 14044 series (ISO 14040, ISO 14044), the Federal Highway Administration's (FHWA's) Pavement LCA Framework (Harvey et al. 2016) and the ILCD Handbook (European Commission - Joint Research Centre - Institute for Environment and Sustainability 2010).

\subsection{Goal and scope definition}

\subsubsection{Intended applications}

This study aims to perform a comparative attributional LCA of traditional Italian asphalt mixtures and certain innovative mixtures containing different percentages of recycled materials (i.e. RAP and CR), employed in the base course of flexible road pavements. Specifically, the CR obtained from processing ELTs (ambient grinding and devulcanisation process) and the RAP coming from the demolition of old road pavements simulating different DoA were considered. The results are compared with those associated with the use of traditional mixtures. They are intended to provide insights on the extent to which recycling based materials, with similar features to those considered in this case study and employed in analogous situations, are efficient in contributing to greening the road pavement sector.

\subsubsection{Reasons for carrying out the $L C A$ study and target audience}

The main reason underlying to the performance of this study has to do with the fact that it is believed to provide valuable information to be incorporated at the early stages in the design of new or in the maintenance of existing pavement structures. The findings of this study are intended to be used by engineering experts and practitioners for evaluating the advantages and disadvantages associated with the use of emerging and commonly called sustainable strategies and practices for road pavement construction, maintenance and rehabilitation (M\&R). Indeed, this study quantifies the potential benefits resulting from the consideration of different DoAs, by developing different equations that show the evolution of the reduction of the scores of each impact category indicator when different DoAs are assumed. Furthermore, the concerned audience is provided with the results of a comparative and seldom performed LCA study between the use of vulcanised and devulcanised rubber in the road pavement construction. 


\subsubsection{Function, functional unit and reference flows}

Function: The different asphalt mixtures are compared considering their main function when used in a structural layer of a road pavement structure. It consists of distributing the traffic loads to the layers beneath, thereby contributing to ensure safe, comfortable, economical and durable driving conditions over a given project analysis period (PAP).

Functional unit: All the asphalt mixtures are compared on the basis of the following functional unit: to enable a given volume of traffic to drive with safe, comfortable, economical and durable conditions in a 1-km-length principal Italian rural roadway, located in Empoli (Tuscany), with 2 carriageways and 4 lanes and a base course which is $10 \mathrm{~cm}$ thick and $15 \mathrm{~m}$ wide. The thickness is equal for all the alternatives since it is assumed that all the solutions have the same durability. The rationale behind this assumption is presented later in this paper with more detail.

Reference flows: Considering that all the alternative asphalt mixtures are assumed to have the same durability, the quantity of asphalt mixtures corresponding to their unitary application in the base course with the dimensions described above is considered as the reference flow.

In total, eleven asphalt mixtures, intended to be applied in base course, are considered in the case study: the traditional mixture and 10 alternative mixtures with recycled materials (i.e. CR and RAP).

To understand the potential environmental advantages and disadvantages related to the use of asphalt mixtures with recycled materials, different percentages of RAP and CR are considered and compared with the reference scenario corresponding to the production and placement of a classical asphalt mixture, hereafter named 'Base', with $4.5 \%$ of bitumen by weight of mixture. The mixtures considered have the features described below (the percentages are given by weight of mixture):

Table 1. Composition of the different asphalt mixtures containing CR used in the base course.

\begin{tabular}{|c|c|c|c|}
\hline $\begin{array}{l}\text { Name of } \\
\text { mixture }\end{array}$ & Description & $\begin{array}{l}\text { Quantity of CR } \\
\text { (kg per ton of } \\
\text { mixture) }\end{array}$ & $\begin{array}{c}\text { Quantity of } \\
\text { bitumen (kg per } \\
\text { ton of mixture) }\end{array}$ \\
\hline Base & $\begin{array}{l}\text { Traditional asphalt mixture } \\
\text { (4.5\% of bitumen) }\end{array}$ & 0 & 45 \\
\hline DRY1.5D & $\begin{array}{l}\text { Rubberised asphalt mixture } \\
\text { (dry process) with } \\
\text { devulcanised rubber (1.5\% } \\
\text { of rubber and } 5.5 \% \text { of } \\
\text { bitumen) }\end{array}$ & 15 & 55 \\
\hline DRY2.0D & $\begin{array}{l}\text { Rubberised asphalt mixture } \\
\text { (dry process) with } \\
\text { devulcanised rubber ( } 2.0 \% \\
\text { of rubber and } 6.0 \% \text { of } \\
\text { bitumen) }\end{array}$ & 20 & 60 \\
\hline DRY1.5V & $\begin{array}{l}\text { Rubberised asphalt mixture } \\
\text { (dry process) with } \\
\text { vulcanised rubber (1.5\% of } \\
\text { rubber and } 5.5 \% \text { of } \\
\text { bitumen) }\end{array}$ & 15 & 55 \\
\hline DRY2.0V & $\begin{array}{l}\text { Rubberised asphalt mixture } \\
\text { (dry process) with } \\
\text { vulcanised rubber ( } 2.0 \% \text { of } \\
\text { rubber and } 6.0 \% \text { of } \\
\text { bitumen) }\end{array}$ & 20 & 60 \\
\hline
\end{tabular}

- DRY1.5D - rubberised asphalt mixture (RUMAC dry process) containing $1.5 \%$ of devulcanised $\mathrm{CR}$ and $5.5 \%$ of bitumen

- DRY2.0D - rubberised asphalt mixture (RUMAC dry process) containing $2.0 \%$ of devulcanised CR and $6.0 \%$ of bitumen

- DRY1.5 V - rubberised asphalt mixture (RUMAC dry process) containing $1.5 \%$ of vulcanised CR and $5.5 \%$ of bitumen

- DRY2.0 V - rubberised asphalt mixture (RUMAC dry process) containing $2.0 \%$ of vulcanised CR and $6.0 \%$ of bitumen

- RAP40BR - asphalt mixture with $40 \%$ of RAP in partial substitution of virgin aggregates. This scenario considers that the bitumen trapped in RAP behaves as black rock (Shirodkar et al. 2011), and then it is not active in the new asphalt mixture. Therefore, the percentage of the VB to be added to the mixture cannot be reduced and was kept equal to $4.5 \%$

- RAP40DoA20, RAP40DoA50, RAP40DoA70, RAP40DoA80 - asphalt mixtures with $40 \%$ of RAP in partial substitution of virgin aggregates. This scenario considers that the bitumen trapped in RAP partially blends (DoA equal to $20,50,70$ and $80 \%$ ) with the VB.

- RAP40FB - asphalt mixture with $40 \%$ of RAP in partial substitution of virgin aggregates. This scenario considers that $100 \%$ of aged bitumen, trapped in the RAP, is being reactivated. The RAP binder content is $5.3 \%$. Therefore, it is necessary to add $2.4 \%$ of VB in order to have a final content of $4.5 \%$ of total bitumen by weight of the mixture.

The bitumen selected for the RUMAC dry process mixture is similar to the one used for the traditional asphalt (FHWA 1997). The size of rubber grains ranges from 4.75 to $0.075 \mathrm{~mm}$. The target air voids content of the asphalt mixture was defined to be equal to $3 \%$. The compositions of DRY1.5D, DRY1.5 V, DRY2.0D and DRY2.0 V mixtures were obtained from the mix design performed in previous studies in which were shown that higher amounts of rubber can inhibit a satisfactory compaction in the laboratory of dense graded asphalt mixtures due to the elastic behaviour of the rubber (Bressi et al. 2018a). Due to this reason, higher percentages of rubber were not considered. Moreover, rubber absorbs the oil fraction of bitumen in the so-called maturation process (Dong et al. 2012); this causes the swelling of the CR particles and leads to the need of adding higher quantity of VB. Indeed, when the rubber is added to the asphalt mixture by means of the dry process, the grains of rubber swell up because they absorb part of the volatile parts of bitumen (paraffin and maltenes). This process of maturation, called 'maceration', originates a stiffer bitumen (Dong et al. 2012), therefore increasing the quantity of bitumen necessary to achieve the optimal mix design of the CR mixtures. Tables 1 and 2 summarise the composition of each asphalt mixture used as alternative to the traditional asphalt mixture.

\subsection{4. $\mathrm{LCl}$ modelling framework}

Given that the use of the new asphalt mixtures is not expected to have large structural changes in the market, the decision context falls into the situation A in the ILCD Guideline (European Commission - Joint Research Centre - Institute for 
Table 2. Composition of the different asphalt mixtures containing RAP with different simulations of the Degree of binder Activation used in the base course.

\begin{tabular}{|c|c|c|c|c|c|c|c|}
\hline $\begin{array}{l}\text { Name of } \\
\text { mixture }\end{array}$ & $\begin{array}{c}\text { Percentage of } \\
\text { RAP (\%) }\end{array}$ & $\begin{array}{l}\text { Quantity of RAP } \\
\text { (kg per ton of } \\
\text { mixture) }\end{array}$ & $\begin{array}{l}\text { Degree of binder } \\
\text { Activation (DoA) } \\
(\%)\end{array}$ & $\begin{array}{c}\text { Activated old } \\
\text { binder (\%) }\end{array}$ & $\begin{array}{c}\text { Percentage of virgin } \\
\text { bitumen added to the } \\
\text { mixture (\%) }\end{array}$ & $\begin{array}{l}\text { Quantity of bitumen } \\
\text { added to the mixture } \\
\text { (kg per ton of mixture) }\end{array}$ & $\begin{array}{l}\text { Quantity of virgin } \\
\text { aggregates (kg per } \\
\text { ton of mixture) }\end{array}$ \\
\hline Base & 0 & 0 & 0 & - & 4.5 & 45 & 555 \\
\hline RAP40BR & 40 & 400 & 0 & 0 & 4.5 & 45 & 555 \\
\hline RAP40DoA20 & 40 & 400 & 20 & 0.4 & 4.1 & 41 & 559 \\
\hline RAP40DoA50 & 40 & 400 & 50 & 1.0 & 3.5 & 35 & 565 \\
\hline RAP40DoA70 & 40 & 400 & 70 & 1.5 & 3.0 & 30 & 570 \\
\hline RAP40DoA80 & 40 & 400 & 80 & 1.7 & 2.8 & 28 & 572 \\
\hline RAP40FB & 40 & 400 & 100 & 2.1 & 2.4 & 24 & 576 \\
\hline
\end{tabular}

${ }^{\mathrm{a}}$ The total bitumen content active in the mixture is always $4.5 \%$.

Environment and Sustainability 2010), i.e. micro-level, product or process-related decision support studies. As such, the attributional approach that depicts the actual or forecasted specific or average supply chain was chosen as the life cycle inventory (LCI) modelling framework (Hertwich 2014).

\subsubsection{System boundaries}

The system boundaries include all the activities required to construct the asphalt base course. Specifically, the following phases are accounted for: (i) resources extraction and composite materials production; (ii) movement involved in hauling the materials between facilities and work site; and (iii) construction equipment operation during the construction of the base course. Furthermore, in this research work the existing literature on the durability and performance of asphalt mixtures containing CR (dry process) and/or RAP is taken into account. In this context, according to several studies (McDaniel et al. 2000, Cao 2007, Farina et al. 2017), the performance of mixtures containing dry $\mathrm{CR}$ and RAP can be considered to be similar to that of traditional mixtures if they are properly designed to avoid non negligible problems related to homogeneity and compaction of the mixture (Santagata et al. 2016). A few others studies, instead, report higher performance (Airey et al. 2003, Huang et al. 2004, Hernandez-Olivares et al. 2009). In the particular case of the devulcanisation process, it emerges that at low temperatures the asphalt mixtures containing devulcanised rubber perform better than traditional ones. Nevertheless, at high temperatures, the devulcanised rubber provides only a modest improvement, because the elastic properties of the rubber are damaged due to the devulcanisation/ depolymeration effect (Han et al. 2016). These materials, in particular the RUMAC technology analysed in this paper, have also been tested several times in test sections showing contradictory results. For instance, the two dry process sections constructed by the Minnesota Department of Transportation (MNDOT) have not shown higher performance compared to traditional asphalt (Turgeon 1989). The Washington State DOT (Estakhri et al. 1992) concluded that the RUMAC dry process did not provide improved performance compared to conventional asphalt. Therefore, a conservative approach assuming the same durability for all the solutions was considered. That means that the maintenance, dismantling and disposal phases are scheduled at the same time for all the solutions and then were excluded from the system boundaries. Indeed, a cradle-to-gate model is appropriate when the materials do not differ in durability, i.e. they have same construction, transport implications, maintenance and EOL management (European Commission - Joint Research Centre - Institute for Environment and Sustainability 2010). Due to these facts, these phases were excluded from the compared systems. This approach has also been adopted in recent studies comparing the use of materials with RAP in infrastructures, when the durability was similar (Porot et al. 2016). Usually the use of RAP percentages below $30-40 \%$ does not require specific technologies, such as separate parallel drum or the use of additives, to overcome technical issues. These percentages allow achieving the same durability as that of traditional mixtures without the employment of particular technologies. Therefore, a cradle-to-gate approach could have been considered (Porot et al. 2016).

However, the modelling approach actually considered in this case study can be named as cradle-to-lay, in the sense that the construction and transportation of materials phases were also considered. An elaborated description of the phases considered in this case study is provided in the next sections.

\subsection{Life cycle inventory}

The LCI phase consists of the primary and secondary data collection and the modelling of the system.

\subsubsection{Data collection and system modelling per life cycle phase}

Primary data are specifically related to the processes associated with the product or service studied in the LCA. The transportation distances of raw materials to the plant are an example of primary data. In turn, secondary data represent generic or average data for the product or service subjected to an analysis. The provenience of that data includes literature, research groups, national and international database and expert's opinion (European Commission - Joint Research Centre Institute for Environment and Sustainability 2010).

In this work, both primary and secondary data were considered as detailed in the following subparagraphs. The data sources were selected in order to be as much time, geographical and technological representative as possible. That means that the most recent and truthful data representing Italian processes and conditions were used as inputs when modelling the processes covered by the subcomponents integrating the system boundaries. The Ecopneus document (Ecopneus 2013) was used as main reference for conducting the LCI of asphalt mixtures containing alternative materials. Reference values for the productivity and working hours of the machinery (pavers and rollers) considered for the laying down and compaction 
operations of the asphalt mixtures applied in the base course were collected from literature (Autostrade per l'Italia 2011). For completing the data set and modelling the background system, the Construction materials (CM) database extension of the Gabi software was used.

\subsubsection{Materials extraction and composite materials in production phase}

2.2.2.1. Virgin aggregates and bitumen production sub-phase. The virgin aggregates required for the base course were modelled as crushed gravel and the inventory data associated with their production were obtained from the CM database considering the percentage of the material passing at different sieves in a typical grading curve of base course. The dataset crushed rock $16-32 \mathrm{~mm}$ (40\% of aggregates), crushed stone $2-15 \mathrm{~mm}$ (30\% of aggregates) and crushed sand $0-2 \mathrm{~mm}$ (30\% of aggregates) were selected. It comprises all the flows of materials and energy associated with the extraction in the quarry, the cleaning, the two stages of crushing and organisation of the production. The finished product is the crushed gravel (dried) at the factory gate. The CM database was also used as the data source for modelling the bitumen production. In this case, the dataset 'Bitumen at refinery; from crude oil; production mix, at refinery EU-27' was selected from the Professional database in Gabi software. This dataset covers the entire supply chain of the refinery products. That includes drilling, crude oil production and processing as well as the transportation of crude oil via pipeline to the refinery. The production includes several aspects, such as energy consumption, transport distances, crude oil processing technologies, feedstock that are individually considered for each crude oil production country. The inventory is mainly based on industry data and it is completed, where necessary, by secondary data.

\subsubsection{Crumb rubber (CR) production sub-phase. A 'cut-off'} approach was adopted for the evaluation of the burdens and benefits associated with the use of this recycled material. According to this approach, only the impacts of the recycling process are attributed to the second life cycle, while all the processes related to the production of the material before 'waste' are attributed to the first life cycle (Schrijvers et al. 2016). Therefore, only the burdens directly associated with the

Table 3. Input and output flows associated with the CR production process.

\begin{tabular}{|c|c|c|}
\hline & Quantity & Unit \\
\hline \multicolumn{3}{|l|}{ Input flow } \\
\hline Diesel mix at refinery EU- $28^{\mathrm{a}}$ & 0.038 & $\mathrm{~kg}$ \\
\hline IT: Electricity mix grid production ${ }^{\mathrm{b}}$ & 20.7 & MJ \\
\hline Lubricating oil & 0.001 & $\mathrm{~kg}$ \\
\hline Tap water, at user & 3.3 & $\mathrm{~kg}$ \\
\hline Steel blade & 0.004 & $\mathrm{~kg}$ \\
\hline Scrap tires & 21.8 & $\mathrm{~kg}$ \\
\hline \multicolumn{3}{|l|}{ Output flow } \\
\hline CR (module created) & 15 & $\mathrm{~kg}$ \\
\hline Recycled fibres & 2.4 & $\mathrm{~kg}$ \\
\hline Steel scrap product & 4.35 & $\mathrm{~kg}$ \\
\hline
\end{tabular}

Notes: ${ }^{\text {aTh }}$ Ths module includes the steam treatment and allows quantifying all the outputs of the diesel production. ${ }^{b}$ It refers to the production and importation of energy in Italy, including all types of energy. It also includes losses, calculated as average values. product itself (crumb rubber) were accounted for. This method allows the analysis when no data are available for the materials coming from outside the system being considered (Ekvall and Tillman 1997). Two different rubber treatments were analysed: (i) the ambient grinding without chemical treatment of the rubber, which produces vulcanised rubber, and (ii) the devulcanisation process, which includes the rubber powder preparation (shredding and granulating), devulcanisation (mainly desulfurisation) and refining of the rubber. All the stages of the rubber reclamation are schematically represented in Figure 1.

Based on Figure 1, new processes related to the CR recycling, such as rubber preparation (shredding and granulating), devulcanisation, refining and collection in plastic big bag, were created specifically for this analysis by collecting information from recent studies (Ecopneus 2013, Li et al. 2014) and by using the CM database.

Shredding and granulating. The shredding and granulating is the first phase of the rubber reclamation process, where the tires are crushed and broken into small pieces and the remaining steel and fibres are removed magnetically. This process is performed with a combination of shaking screens and wind sifters, without any chemical treatment of the rubber.

In this phase, the environmental impacts of the following processes were taken into account: (i) transport of materials from the collection platform to the crushing plant; (ii) crushing and separation of the fibres and metal from the rubber and (iii) sieving of different fractions. For the shredding and granulating phase, it was necessary to build another sub-process: Steel blade to crush the scrap tires conveyed in the batch through a conveyor belt for the shredding and granulating.

For the steel blade production, the processes selected were the following: (i) steel production; (ii) hot rolling and (iii) sheet rolling. The data set represents the steel production based on the main production steps that take place within an integrated steel plant. The LCI of the steel blade production process was collected from the recent study (Farina et al. 2017) and it is represented by the processes 'IT: electricity mix [supply mix]' (0.00103 MJ), 'Steel, converter, unalloyed, at plant', 'Sheet rolling, steel [processing]' present in CM database. The input/output flows of materials and energy sources were calculated as the average value of the data collected from the Italian crushing plants.

The CR production is a multi-output process. Indeed, from shredding and granulating the scrap tires in specialised plants, three main elements can be obtained: (i) CR (that will be used in the asphalt mixtures); (ii) scrap steel and (iii) textile. Therefore, the allocation of all the outputs was conducted according to the mass approach by using the following percentages: $69 \%$ for the CR output; $20 \%$ for the scrap steel output and $11 \%$ for the textile output (Farina et al. 2017). Despite the high market value of steel, steel scrap was not assumed to undergo recycling due to the high operational complexity of separating the scrap steel from residual rubber. Table 3 summarises the input and output flows of the $\mathrm{CR}$ production process for producing $15 \mathrm{~kg}$ of rubber (1.5\% of 1 ton of asphalt mixture).

Devulcanisation and refining. All the input and outputs of the devulcanisation process were collected from literature ( $\mathrm{Li}$ et al. 2014). Specifically, plasticisers (pine tar and rosin) were 


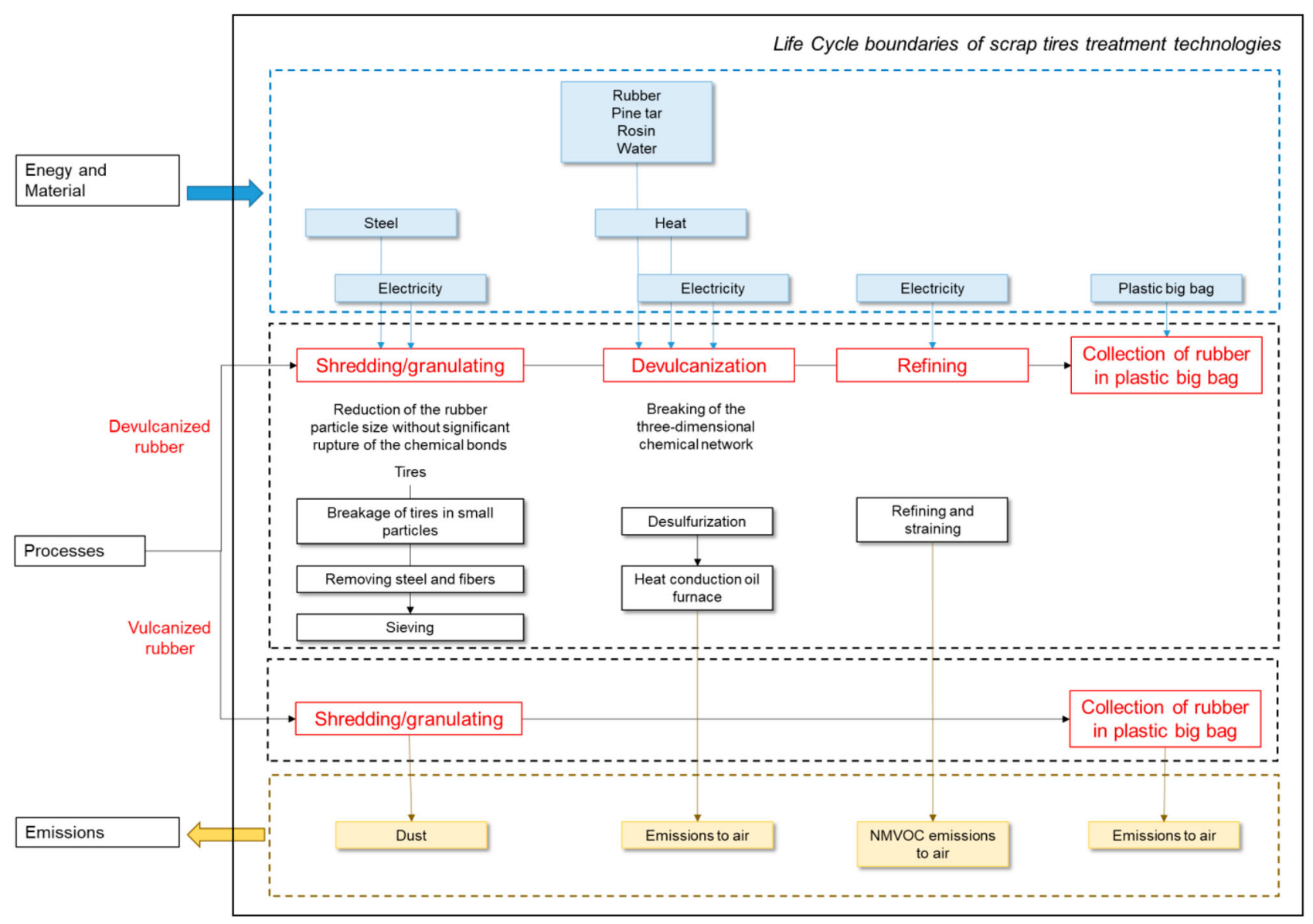

Figure 1. Rubber reclamation stages: rubber preparation, devulcanisation, refining and collection of rubber in plastic big bag.

considered to be added to improve rubber plasticity after the shredding process. Pine tar is a viscous and sticky liquid obtained from pine through destructive distillation. Rosin is

Table 4. Input and output flows associated with the devulcanisation and refining processes. The quantities refer to the treatment of $15 \mathrm{~kg}$ of rubber.

\begin{tabular}{|c|c|c|c|}
\hline Process & Item & Quantity & Unit \\
\hline \multirow[t]{14}{*}{ Devulcanisation } & Input flow & & \\
\hline & Coal tar [organic intermediate products] & 0.15 & $\mathrm{~kg}$ \\
\hline & $\begin{array}{l}\text { IT: electricity, high voltage, production IT, } \\
\text { at grid [production mix] }\end{array}$ & 68.2 & MJ \\
\hline & Purchased rubber powder [plastic parts] & 7.35 & $\mathrm{~kg}$ \\
\hline & RER: rosin size, at plant [organics] & 0.15 & $\mathrm{~kg}$ \\
\hline & RER: tap water, at user & 0.15 & $\mathrm{~kg}$ \\
\hline & Rubber [consumer waste] & 7.35 & $\mathrm{~kg}$ \\
\hline & Output flow & & \\
\hline & Devulcanised rubber & 15 & $\mathrm{~kg}$ \\
\hline & $\begin{array}{l}\text { Charcoal (loaded) [hazardous waste for } \\
\text { recovery] }\end{array}$ & 0.675 & $\mathrm{~kg}$ \\
\hline & Carbon dioxide [inorganic emissions to air] & 5.63 & $\mathrm{~kg}$ \\
\hline & $\begin{array}{l}\text { Different pollutants [other emissions to } \\
\text { industrial soil] }\end{array}$ & 0.0248 & $\mathrm{~kg}$ \\
\hline & $\begin{array}{l}\text { Nitrogen oxides [inorganic emissions to } \\
\text { fresh water] }\end{array}$ & 0.0105 & $\mathrm{~kg}$ \\
\hline & $\begin{array}{l}\text { Sulphur dioxide [Inorganic emissions to air] } \\
\text { Input flow }\end{array}$ & 0.00675 & $\mathrm{~kg}$ \\
\hline \multirow{5}{*}{ Refining } & Devulcanised rubber & 15 & $\mathrm{~kg}$ \\
\hline & $\begin{array}{l}\text { IT: electricity, high voltage, production IT, } \\
\text { at grid [production mix] }\end{array}$ & 14.4 & MJ \\
\hline & Output flow & & \\
\hline & Recycled crumbrubber & 15 & $\mathrm{~kg}$ \\
\hline & $\begin{array}{l}\text { NMVOC, unspecified origin [ecoinvent } \\
\text { long-term to air] }\end{array}$ & 0.000555 & $\mathrm{~kg}$ \\
\hline
\end{tabular}

a solid resin obtained from the oil of pine trunk. The desulfurisation tank is kept at a high temperature (approximately $230^{\circ}$ C) and under pressure (2.2 MPa). The waste gas discharged in two different moments was treated. The first gas steam is discharged from the desulfurisation tank, after it is cooled and decompressed. Finally, a gas absorber with sodium carbonate is used to remove almost entirely the contaminants from the steam. The other one is discharged from the heat conduction oil furnace and consists mainly of $\mathrm{CO}_{2}, \mathrm{NO}_{\mathrm{X}}$ and $\mathrm{SO}_{2}(\mathrm{Li}$ et al. 2014). A wet-flue gas desulfurisation system, which relies on $96 \%$ efficiency in dust collection and $75 \%$ desulfurisation efficiency, was used. After the devulcanisation process, the rubber is reprocessed in the refining stage where non-methane volatile organic compounds (NMVOC) are collected and absorbed with an efficiency of $80 \%$. After that, they are released to the atmosphere. Table 4 reports the input and output of the devulcanisation and refining processes.

Collection of rubber in plastic big bag. The last step is represented by the collection of rubber grains in plastic bag to be transported to an asphalt mix plant. It was assumed that the plastic big bag used for collecting the different fractions of rubber grains are composed of $90 \%$ of polypropylene and $10 \%$ of polyethylene. The process contains all the operations and burdens for the transformation of raw plastic into the final product. The LCI data of the plastic big bag production was collected from recent studies (Ruban 2012) and summarised in Table 5. To collect $15 \mathrm{~kg}$ of rubber, i.e. final product 
to transport to the asphalt plant for producing 1 ton of asphalt mixture (DRY1.5D and DRY1.5 V), $0.028 \mathrm{~kg}$ of plastic big bag is needed (Farina et al. 2017).

2.2.2.3. RAP production sub-phase. For the RAP production, the 'cut-off' approach was also adopted. This approach has been selected because the milling of RAP from the previous pavement and its transportation to the plant were assumed as EOL activities from the previous life cycle system (Yang 2014). In this case study, it was considered that once removed from road pavement, the RAP is transported directly to the asphalt plant where it is stored in special sites and subjected to screening and down-sizing operations. For the RAP handling, the common production rates of the several machines were considered when determining the energy requirements. The LCI data related to the production and distribution of those energy sources was taken from the CM database. Moreover, the treatment of the RAP at the plant requires a certain amount of energy for sieving and eventually crushing the recycled material. This amount of energy was considered to be equal to $0.0212 \mathrm{MJ}$ per $\mathrm{kg}$ of RAP (Zaumanis et al. 2012).

2.2.2.4. Asphalt mixtures production sub-phase. The asphalt mixture production activities take place in the hot mix production plant. The processes CR production, aggregates production, RAP production and bitumen production already described were created and fed into the process for the fabrication of the asphalt mixtures. The electricity for the production of 1 ton of any asphalt mixture was considered to be equal to $160 \mathrm{kWh}$ (Ecopneus 2013) based on the assumption that the mixing temperature is the same regardless of the mixture being produced (Farina et al. 2017). In this case study, the electricity was used to operate a discontinuous batch with a gas burner with a power of $580 \mathrm{~kW}$.

\subsubsection{Construction phase}

To build an asphalt layer in a road pavement, it is necessary to lay down the asphalt mixture with a paver and compact it in order to achieve the desired thickness of $10 \mathrm{~cm}$. The fuel combustion-related emissions associated with the operation of each construction equipment were determined by combining the LCI data corresponding to the process 'machine operation, diesel, $>=74.57 \mathrm{~kW}$, high load factor' existing in the CM database with the hourly productivity of

Table 5. Inventory referring to the production of $1 \mathrm{~kg}$ of plastic big bag.

\begin{tabular}{lll}
\hline Item & Quantity & Unit \\
\hline Input flow & & \\
Diesel [refinery products] & $6.81 \mathrm{E}-05$ & $\mathrm{~kg}$ \\
Polyethylene foam [plastics] & 1 & $\mathrm{~kg}$ \\
Polyethylene low density granulate (LDPE/PE-LD) [plastics] & 0.1 & $\mathrm{~kg}$ \\
Polypropylene granulate (PP) [plastics] & 0.9 & $\mathrm{~kg}$ \\
Emissions to air and water & & \\
Butyl acetate [ecoinvent long-term to air] & 0.0097 & $\mathrm{~kg}$ \\
Carbon dioxide [Inorganic emissions to air] & 0.00041 & $\mathrm{~kg}$ \\
Carbon monoxide [Inorganic emissions to air] & $8.06 \mathrm{E}-06$ & $\mathrm{~kg}$ \\
Ethanol [ecoinvent long-term to air] & 0.00194 & $\mathrm{~kg}$ \\
Methane [organic emissions to fresh water] & $3.26 \mathrm{E}-08$ & $\mathrm{~kg}$ \\
Nitrogen dioxide [inorganic emissions to air] & $4.10 \mathrm{E}-06$ & $\mathrm{~kg}$ \\
Sulphur oxides [inorganic emissions to air] & $5.00 \mathrm{E}-07$ & $\mathrm{~kg}$ \\
Toluene [ecoinvent long-term to air] & 0.00399 & $\mathrm{~kg}$ \\
\hline
\end{tabular}

$200 \mathrm{ton} / \mathrm{h}$ for the operations of the paver and $150 \mathrm{ton} / \mathrm{h}$ for the roller involved in the pavement construction activities. By considering fuel consumption rates of $30 \mathrm{l} / \mathrm{h}$ and $17 \mathrm{l} / \mathrm{h}$ (Autostrade per l'Italia 2011), respectively for a paver and a roller, the total fuel consumption was calculated as $585 \mathrm{l} / \mathrm{km}$ (paver) and $332 \mathrm{l} / \mathrm{km}$ (roller). The consumptions were considered to be the same for all the asphalt mixtures studied. Indeed, regardless of the fact that recent studies (Bressi et al. 2018a) have demonstrated the need of higher compaction efforts for dry mixtures in the laboratory, there is no practical link between laboratory increased compaction efforts and in-situ compaction in terms of the number of roller passages.

The airborne emissions released by the construction equipment during the lay down and compaction operations of the asphalt layers are expected to increase with the RAP content of the mixtures (Jullien et al. 2006). In that study, the authors investigated the airborne emissions and pollutants released during the construction of a road pavement section where asphalt mixtures with RAP content ranging from $0 \%$ to $30 \%$ were applied. In the case study presented in this paper, the findings reported by Jullien et al. (2006) were extrapolated to predict the additional gaseous emissions for an asphalt mixture with a RAP content of $40 \%$. As far as the CR dry mixtures are concerned, there are no studies in the literature investigating the effects above described. Therefore, for that particular type of mixtures, the airborne emissions and pollutants released during this phase were considered the same as those related to conventional mixtures.

\subsubsection{Transportation of materials phase}

Scrap tyres, crushed gravel limestone, bitumen as well as plastic big bag, steel blade and subsequently CR must be transported between the production facilities, whereas the asphalt mixtures must be transported from the asphalt plant to the construction site. It was assumed that the materials are hauled from the quarry and plants by truck. Therefore, the environmental impacts resulting from the transportation of materials and mixtures were due to the emissions released by the combustion process of the transportation vehicles.

Table 6. Transportation distances considered in the case study and displayed in Figure 2.

\begin{tabular}{|c|c|c|}
\hline $\begin{array}{l}\text { Type of } \\
\text { material }\end{array}$ & $\begin{array}{l}\text { Transport distance } \\
{[\mathrm{km}]}\end{array}$ & Origins/destinations \\
\hline \multicolumn{3}{|c|}{ Bituminous mixtures with $C R$} \\
\hline Steel blade & 286 & $\begin{array}{l}\text { Production of steel blade/Crumb rubber } \\
\text { plant }\end{array}$ \\
\hline Plastic big bag & 286 & $\begin{array}{l}\text { Production of plastic big bag/Crumb } \\
\text { rubber plant }\end{array}$ \\
\hline ELTs & 60 & $\begin{array}{l}\text { ELTs stock/crumb rubber plant } \\
\text { production }\end{array}$ \\
\hline Crumb rubber & 532 & $\begin{array}{l}\text { Crumb rubber plant production/Asphalt } \\
\text { plant }\end{array}$ \\
\hline Bitumen & 100 & Refinery/asphalt plant \\
\hline Aggregates & 75 & Quarry/asphalt plant \\
\hline CR mixtures & 80 & Asphalt plant/construction site \\
\hline \multicolumn{3}{|c|}{ Bituminous mixtures with RAP } \\
\hline RAP & - & RAP stock is present at the asphalt plant \\
\hline Bitumen & 100 & Refinery/asphalt plant \\
\hline Aggregates & 75 & Quarry/asphalt plant \\
\hline RAP mixture & 80 & Asphalt plant/construction site \\
\hline
\end{tabular}




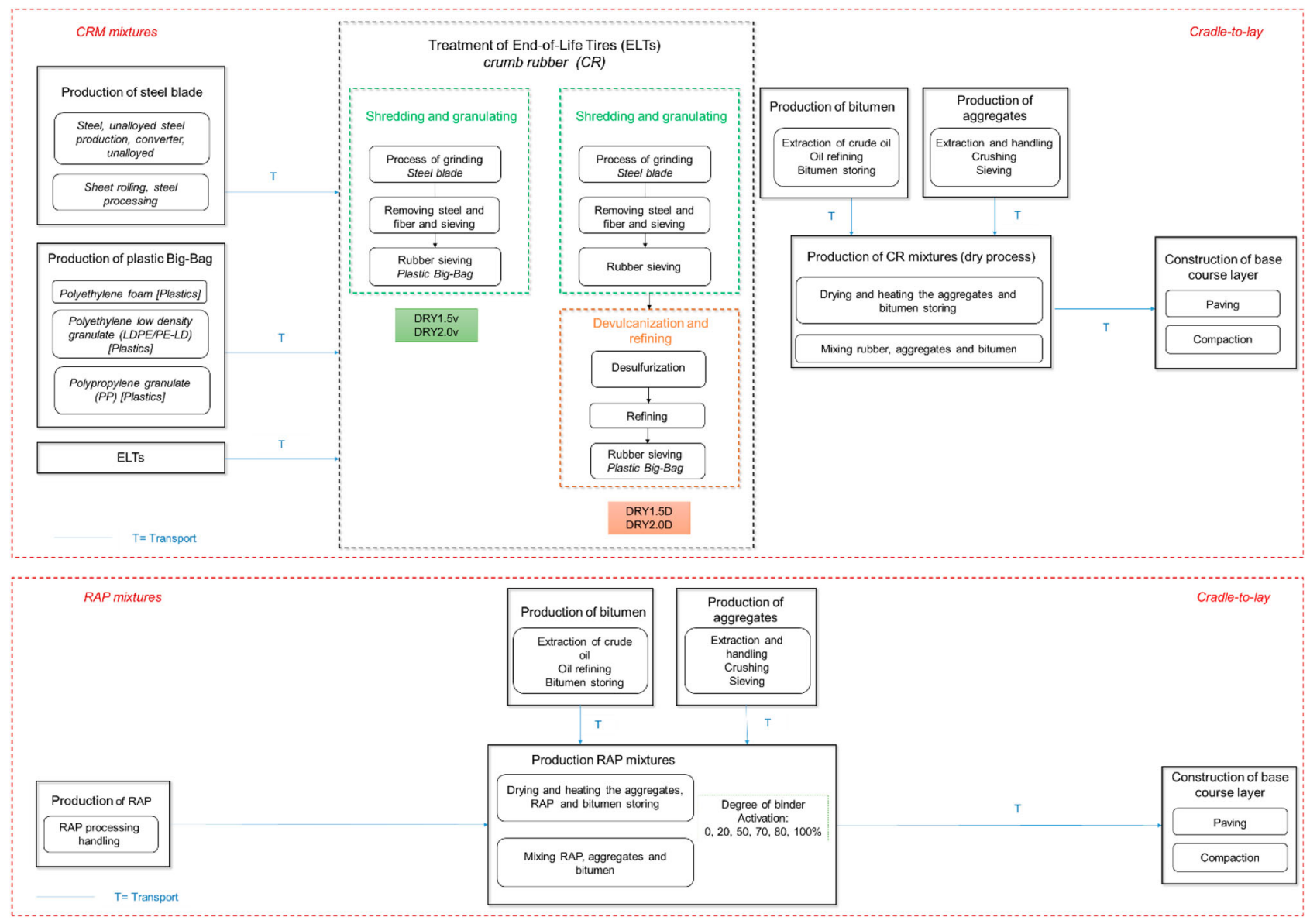

Figure 2. Schematic representation of the processes and transportation distances adopted for the production and placement of the asphalt mixtures with CR and RAP.

The process 'GLO: Truck, Euro 3, 20-26 t gross weight/17.3 t payload capacity ts' existing in the CM database was used to determine the environmental burdens associated with the transportation of materials and mixtures hauled by heavy duty vehicles on the road. The different processes adopted for all the mixtures considered in the case study are outlined in Figure 2. The transport distances between different sites are reported in Table 6.

\subsection{Life cycle impact assessment}

The life cycle impact assessment (LCIA) stage of the standardised LCA methodology comprises several steps, namely, classification, characterisation, normalisation, group and weighting (ISO, 2006). Among these steps, classification and characterisation were undertaken in this study. The characterisation modelling to quantify the potential environmental impacts was performed by applying the impact assessment method ReCiPe at midpoint level, according to the hierarchist perspective (Goedkoop et al. 2013). Specifically, the following impact categories were considered: climate change, fossil depletion, freshwater ecotoxicity, freshwater eutrophication, human toxicity, marine ecotoxicity, marine eutrophication, particulate matter formation, terrestrial acidification, ozone depletion, terrestrial ecotoxicity and water depletion.
Finally, the Gabi Professional Academy LCA software (GaBi ts Software 7.3.3, 2017) was adopted for modelling the processes analysed in this case study.

\subsection{Results and discussion}

The characterised LCIA results are shown in Figures 3 and 4. They highlight different aspects of the environmental performance associated with each alternative considered for the construction of the base course. In particular, Figure 3 displays the potential relative life cycle environmental impacts of the asphalt mixture applied in the base course containing vulcanised or devulcanised CR (i.e. DRY1.5V, DRY2.0V, DRY1.5D and DRY 2.0D) calculated in relation to those of the traditional asphalt mixture. The results are to be understood as follows: negative relative numbers mean that the alternative asphalt mixtures deteriorate the potential life cycle environmental impact results in relation to those associated with the traditional asphalt mixture, while positive numbers represent an improvement of the environmental profile.

It can be observed that not only all the rubberised solutions lead to an increase of the scores of the whole set of impact categories, but also that the type of rubber treatment influences the environmental performance of the different solutions. Indeed, the devulcanisation process leads to a significant increase of the environmental burdens compared to ambient grinding, 


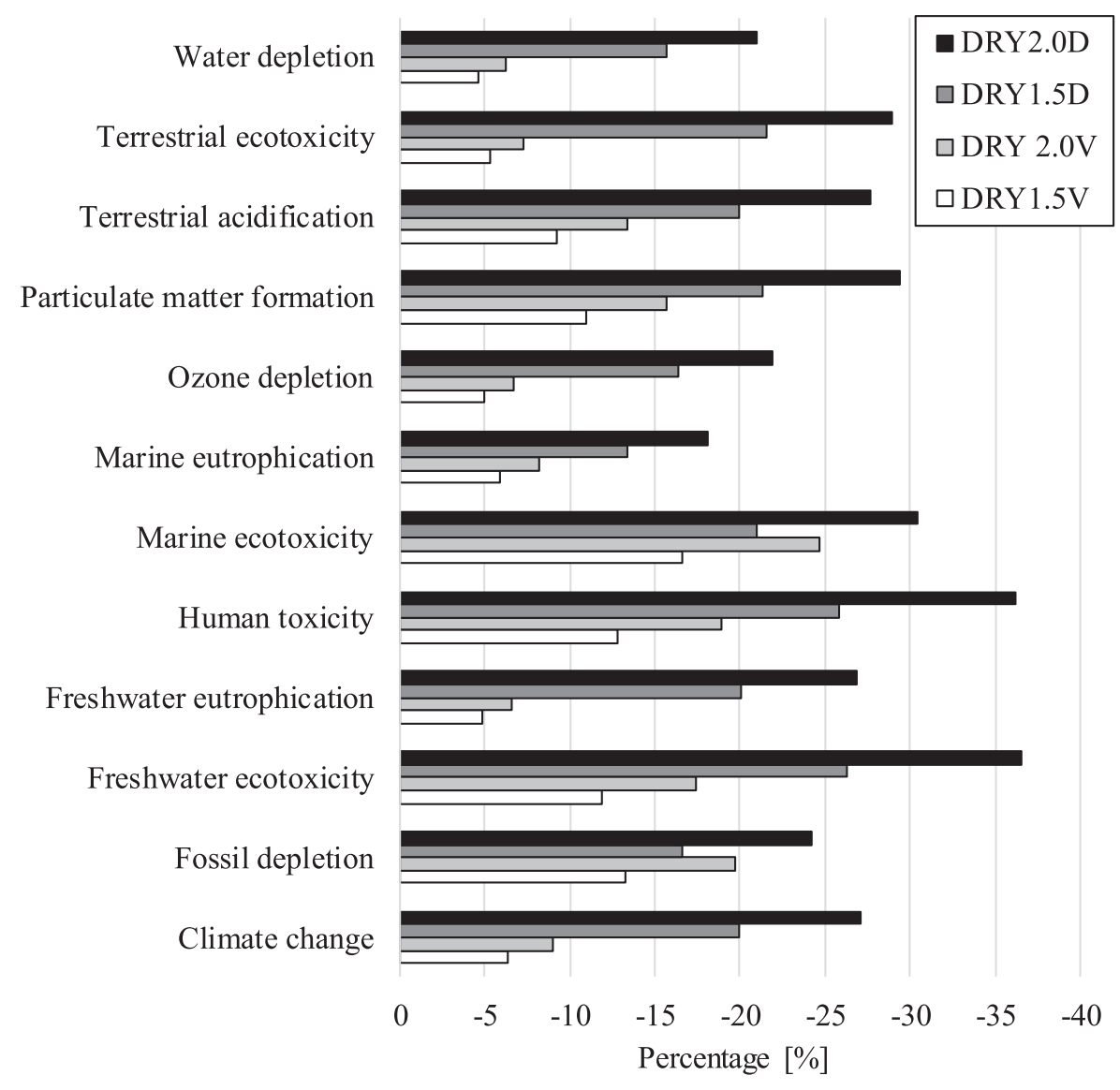

Figure 3. Potential relative life cycle environmental impacts of alternative asphalt mixtures.

especially in the case of the impact categories freshwater ecotoxicity, terrestrial ecotoxicity and water depletion. This can be confirmed in Figure 4 that displays the relative contributions of the several life cycle phases and sub-phases to the total impact category scores of the two types of rubberised asphalt.

As detailed in Figure 4, the asphalt mixtures production and base course construction phases are the main source of impacts for 7 out of 11 impact categories, followed by the bitumen production (4 out of 11 impact categories). In turn, the production of CR (ambient grinding) is responsible by the lowest share of the impact scores. In the case of the asphalt mixtures production and base course construction, their contribution can be as high as $79.0 \%$ and $93.0 \%$ for the impact category particulate matter formation in the solutions DRY2.0D and DRY2.0V, respectively, while the maximum contribution given by the production of bitumen can amount to $69.3 \%$ and $73.2 \%$ for the impact category marine ecotoxicity in the solutions DRY2.0D and DRY2.0V, respectively. Regarding the production of $\mathrm{CR}$, its maximum contribution is observed for the impact category freshwater eutrophication, being equal to $20.3 \%$. This value is the sum of rubber preparation, devulcanisation and refining for DRY2.0D. Instead the maximum contribution related to the ambient grinding for DRY2.0V is recorded for particulate matter formation and it is equal to $3.0 \%$. The devulcanisation and refining processes have the highest environmental burden in the rubber treatment because the desulfurisation requires extensive heat from coal combustion (Li et al. 2014). In this case study, the highest impact category scores are observed in the impact categories water depletion, freshwater eutrophication and climate change. Therefore, to obtain a cleaner production, the focus must be placed on the flue gas treatment in the devulcanisation process. The results presented previously also confirm the findings of other studies that reported the production of $\mathrm{VB}$ to be one of the most environmental damaging and energy demanding processes in the road paving activity (Santero et al. 2011a, Santos et al. 2015, Farina et al. 2017, Bressi et al. 2018b).

Another important remark emerging from the results presented previously is that the use of rubberised asphalt mixtures can only be justified (from an environmental perspective) if the durability of the final product is higher. This is mainly due to the fact that the rubber grains are obtained from crushing scrap tires in specialised plants where they are also separated from steel fibres and textile. All these operations are extra compared to those required for producing conventional asphalt mixtures and the associated environmental burdens are not compensated by the amount of recycled material employed (only $1.5 \%$ or $2 \%$ of CR). From the analysis of Figure 4 it emerges that when only ambient grinding is considered, the $\mathrm{CR}$ production is not directly responsible for the highest impacts category scores of the alternatives proposed. Instead, the higher quantity of bitumen required for the optimal mixture design of the $\mathrm{CR}$ asphalt mixtures leads to considerable effects on the scores of all impact categories, especially those related to the impact category ecotoxicity. On the contrary, when the rubber is devulcanised, the desulfurisation process 

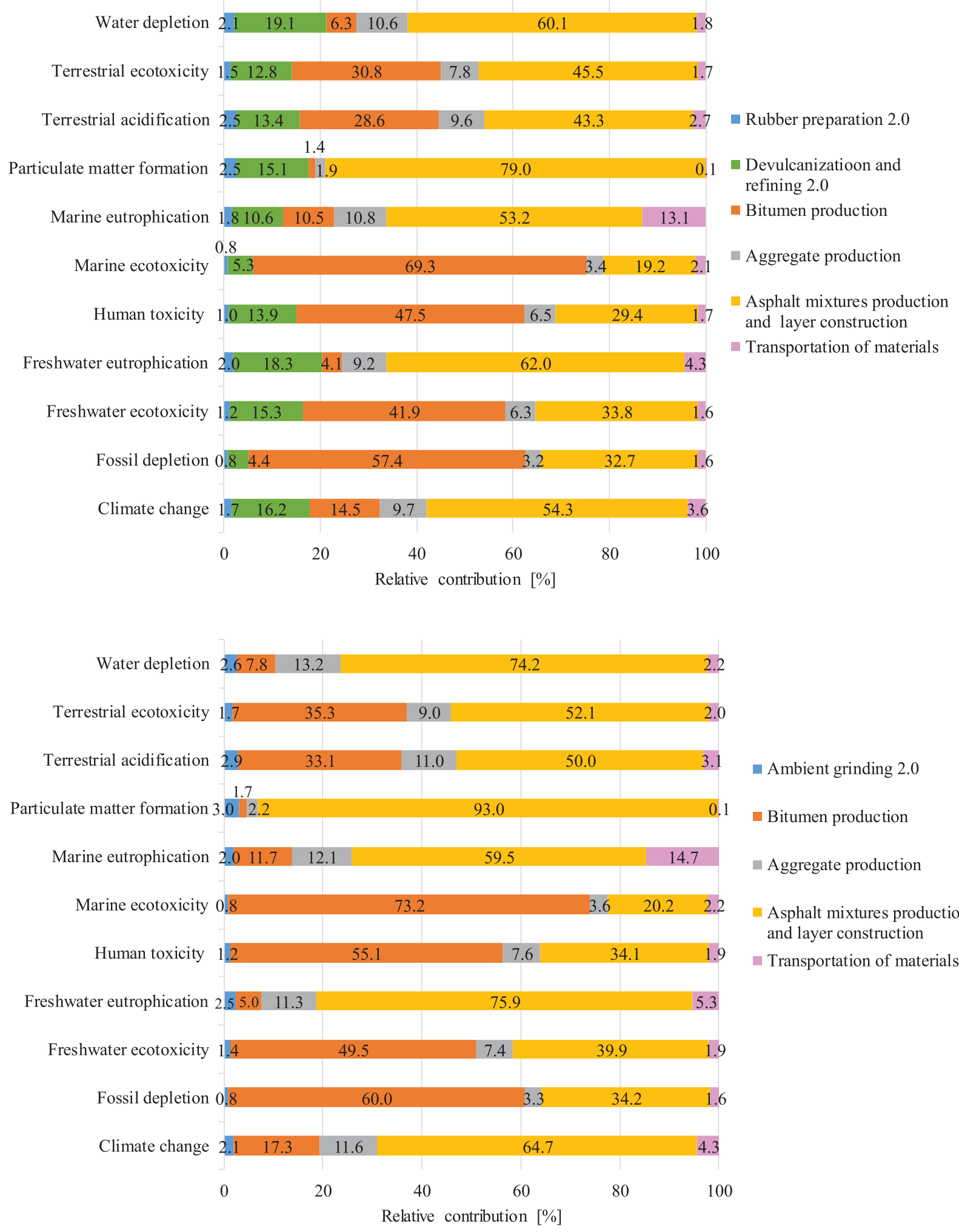

Ambient grinding 2.0

- Bitumen production

Aggregate production

Asphalt mixtures production and layer construction

- Transportation of materials

Figure 4. Relative contribution of the different life cycle phases and subphases for the total environmental impacts due to the use of (a) asphalt mixture with $2.0 \%$ of vulcanised CR and (b) asphalt mixture with $2.0 \%$ of devulcanised CR.

requires an extensive heat from coal combustion, and the emissions of the related flue gas contribute to further increase of the environmental burdens.

Given that there is no clear evidence in the literature that the durability of the dry mixtures is higher than that of traditional mixtures, it was assumed that the life cycle of the layer constructed with the alternative mixtures is equal to that constructed with the traditional mixture. Therefore, the results in terms of durability of the layers and consequently the life cycle environmental profiles might have been different if the wet process had been adopted to produce the alternative rubberised asphalt mixtures. In this case, the chemical treatment of the 
rubber can improve the rheology of the binder, thereby increasing the performance of the overall mixture (Mangili et al. 2015).

Figure 5 shows the potential relative life cycle environmental impacts of the asphalt mixtures containing RAP (RAP40BR and RAP40FB) in relation to those of the traditional asphalt mixture applied in the base course. It can be observed that the solutions containing RAP reduce the impact category scores compared to the reference solution in all the impact categories. In particular, for the solution RAP40BR, which requires a lower quantity of virgin aggregates and the same content of bitumen as that of the reference mixture, the impact categories marine eutrophication (10.02\%), freshwater eutrophication (6.59\%), climate change (6.56\%), terrestrial ecotoxicity $(6.41 \%)$ and particulate matter formation $(6.22 \%)$ show the highest benefits. It should be noted that when considering the full blending between the aged and VB and reducing the quantity of VB to be added to the RAP40FB mixture, the impact categories exhibiting the highest benefits are different: marine ecotoxicity (34.09\%), fossil depletion (27.04\%) human toxicity $(26.83 \%)$, and freshwater ecotoxicity $(24.07 \%)$. This means that the reduction by $40 \%$ of virgin aggregates has a greater effect on certain impact categories, while the bitumen reduction allows further reductions in all the impact categories, especially in the cases of the marine ecotoxicity, fossil depletion and human toxicity.

A more realistic assumption is made when the aged binder existing in RAP is considered to blend partially with the VB. Figure 6 shows the potential life cycle impact category scores obtained when considering different DoA. From that figure it can be seen that as a consequence of the reduction in the use of $\mathrm{VB}$ due to the increase in the DoA, the reduction of the potential life cycle impact scores derived from the incorporation of RAP in the production of asphalt mixtures are globally

Table 7. Equations that provide the potential relative environmental improvement in each impact category depending on the Degree of binder Activation (DoA).

\begin{tabular}{|c|c|c|}
\hline $\begin{array}{l}\text { Impact category } \\
\text { and acronym }\end{array}$ & $\begin{array}{l}\text { Potential relative life cycle } \\
\text { environmental impacts } \\
\text { improvements (\%) }\end{array}$ & $\begin{array}{c}\text { Coefficient of } \\
\text { determination }\left(R^{2}\right)\end{array}$ \\
\hline $\begin{array}{l}\text { Climate change } \\
(C C)\end{array}$ & $\Delta C C=0.063 D o A+6.569$ & 0.999 \\
\hline $\begin{array}{l}\text { Fossil depletion } \\
\text { (FD) }\end{array}$ & $\Delta F D=0.250 D o A+2.283$ & 0.999 \\
\hline $\begin{array}{l}\text { Freshwater } \\
\text { ecotoxicity (FEC) }\end{array}$ & $\Delta F E c=0.201 D o A+4.247$ & 0.999 \\
\hline $\begin{array}{l}\text { Freshwater } \\
\text { eutrophication } \\
\text { (FEu) }\end{array}$ & $\Delta F E u=0.017 D o A+6.591$ & 0.998 \\
\hline Human toxicity $(H T)$ & $\Delta H T=0.227 D o A+4.437$ & 0.999 \\
\hline $\begin{array}{l}\text { Marine ecotoxicity } \\
\text { (MEC) }\end{array}$ & $\Delta M E c=0.317 D o A+2.741$ & 0.999 \\
\hline $\begin{array}{l}\text { Marine } \\
\text { eutrophication } \\
(M E u)\end{array}$ & $\Delta M E u=0.042 D o A+10.023$ & 0.998 \\
\hline $\begin{array}{l}\text { Ozone depletion } \\
(O D)\end{array}$ & $\Delta M O=0.006 D o A+0.971$ & 0.998 \\
\hline $\begin{array}{l}\text { Particulate matter } \\
\text { formation }(P M)\end{array}$ & $\Delta P M=0.125 D o A+6.697$ & 0.985 \\
\hline $\begin{array}{l}\text { Terrestrial } \\
\text { acidification }(T A)\end{array}$ & $\Delta T A=0.135 D o A+5.197$ & 0.991 \\
\hline $\begin{array}{l}\text { Terrestrial } \\
\text { ecotoxicity }(T E)\end{array}$ & $\Delta T E=0.025 D o A+6.724$ & 0.921 \\
\hline $\begin{array}{l}\text { Water depletion } \\
(\text { WD) }\end{array}$ & $\Delta W D=0.003 D o A+2.211$ & 0.949 \\
\hline
\end{tabular}

considerable for all the impact categories and follow a linear relationship. Table 7 displays all the numerical relationships derived from the potential life cycle impact category scores that relate the DoA of aged binder with the potential relative benefit for each impact category.

The table and figure introduced previously show that it is possible to define a ranking of improvement that depends on the VB to be added to the mixture. The ranking of the impact categories that have the highest benefits according to the equations derived from the analysis are reported in Table 8 along with their specific range of improvement. The impact category that benefits the most with the increase in the DoA is clearly the marine ecotoxicity, followed by fossil depletion and human toxicity. On the contrary, the impact categories ozone and water depletion are found to be almost insensitive to changes in the DoA (improvements inferior to $1 \%$ ). Additionally, for DoA values approximately greater than $40 \%$ and lower than $10 \%$, Figure 6 shows that the rankings of impact categories in terms of reductions in the scores remain generally stable. This trend is different from that denoted for DoA values ranging between approximately $10 \%$ and $40 \%$, in which a change in the rankings is observed.

Figure 7 shows the primary energy demand and climate change, expressed in terms of $\mathrm{MJ}$ and $\mathrm{CO}_{2}$-eq. emissions, respectively, derived from the production of asphalt mixtures containing recycled materials in relation to those of the traditional asphalt mixture. From Figure 7, it can be observed that the solutions containing RAP reduce the primary energy demand and the $\mathrm{CO}_{2}$-eq. emissions per ton of material in relation to those associated with the reference solution. The energy required as well as the climate change score decreases when the active aged binder increases, because there is a further reduction of the VB needed to be added to the asphalt mixture. Finally, for all the other environmental impact categories the energy required for producing CRM mixtures increases, especially if the rubber is treated with a devulcanisation process before its use.

\section{Summary, conclusions and perspectives}

Currently, several research efforts are being undertaken to study the behaviour of innovative asphalt mixtures produced

Table 8. Ranking of the impact categories resulting from the differences in the Degree of binder Activation and the consequent reduction of VB consumption.

\begin{tabular}{llc}
\hline Ranking & \multicolumn{1}{c}{ Impact category } & $\begin{array}{c}\text { Range of improvement between black rock } \\
\text { and full blending (\%) }\end{array}$ \\
\hline 1 & Marine ecotoxicity & 31.7 \\
2 & Fossil depletion & 25.0 \\
3 & Human toxicity & 22.7 \\
4 & Freshwater ecotoxicity & 20.1 \\
5 & Terrestrial acidification & 13.5 \\
6 & Particulate matter & 12.5 \\
& formation & 6.3 \\
7 & Climate change & 4.2 \\
8 & Marine eutrophication & 2.5 \\
9 & Terrestrial ecotoxicity & 1.7 \\
10 & Freshwater & \\
& eutrophication & 0.6 \\
11 & Ozone depletion & 0.3 \\
12 & Water depletion &
\end{tabular}




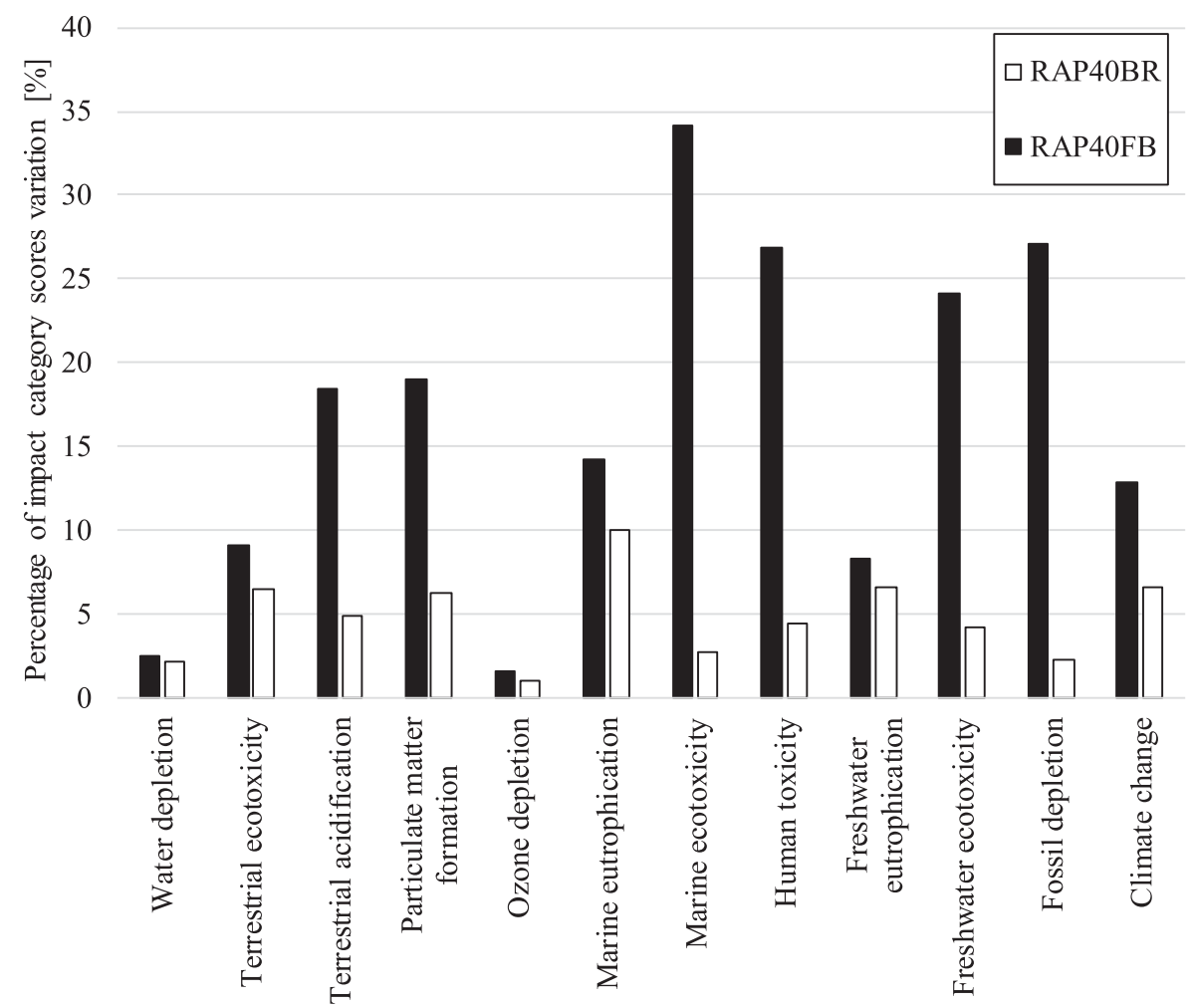

Figure 5. Potential relative life cycle environmental impacts of alternative asphalt mixtures (RAP40BR and RAP40FB) calculated in relation to those of the reference solution, i.e. the traditional asphalt mixture.

with a high content of recycled materials. Nevertheless, the extent to which those mixtures are environmentally friendly remains to be assessed and quantified. Therefore, this paper presents a comparative and attributional LCA of a traditional asphalt mixture employed in the base course of a flexible road pavement and alternative asphalt mixtures containing different percentages of recycled materials, namely RAP and CR.

The LCA is performed from the resource extraction and composite materials production to the placement of the mixtures in the construction site, and including the transportation movement of materials. The results obtained show that:

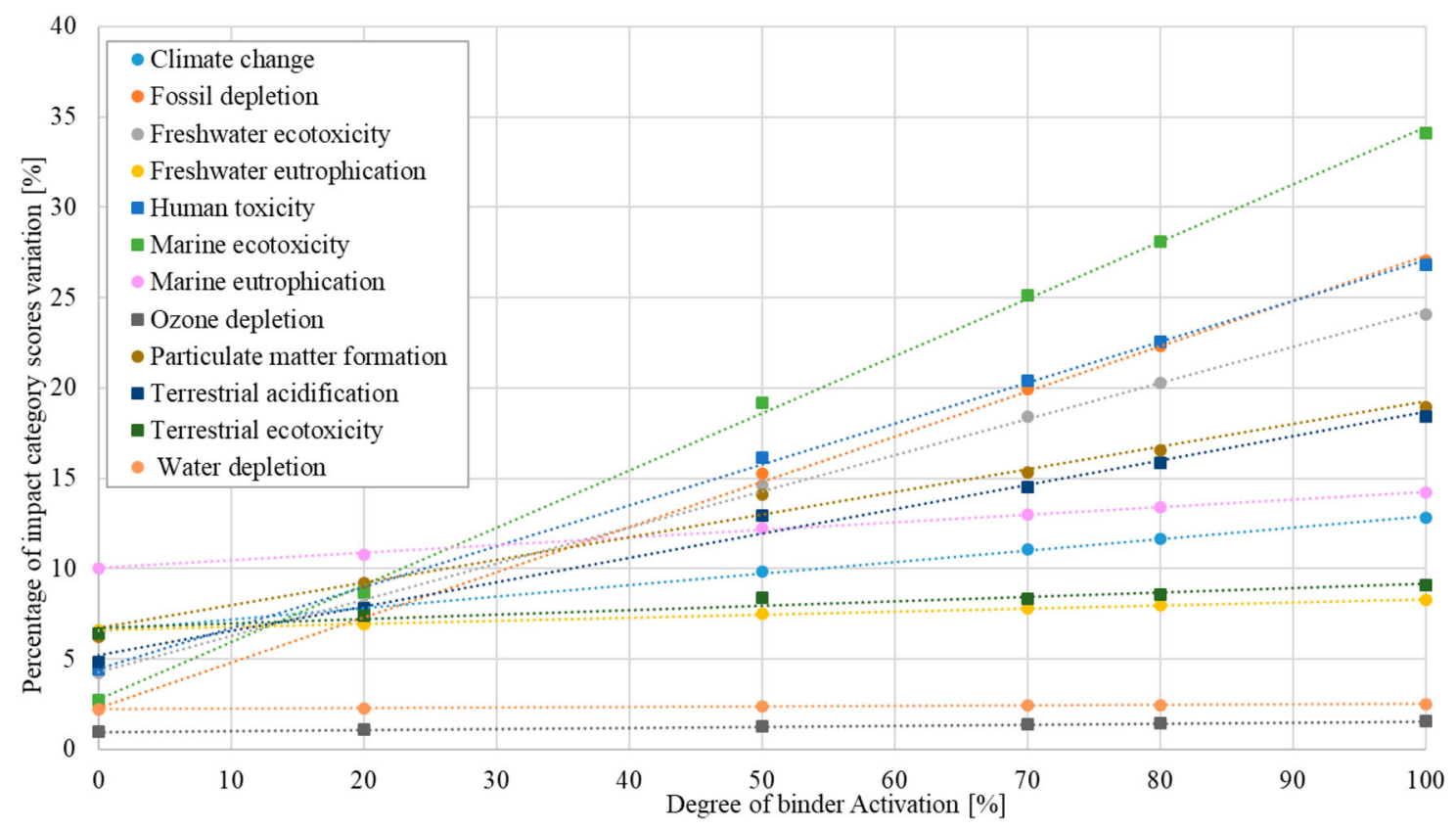

Figure 6. Relationships between the Degree of binder Activation (DoA) and the percentage of environmental benefits for all impact categories. 

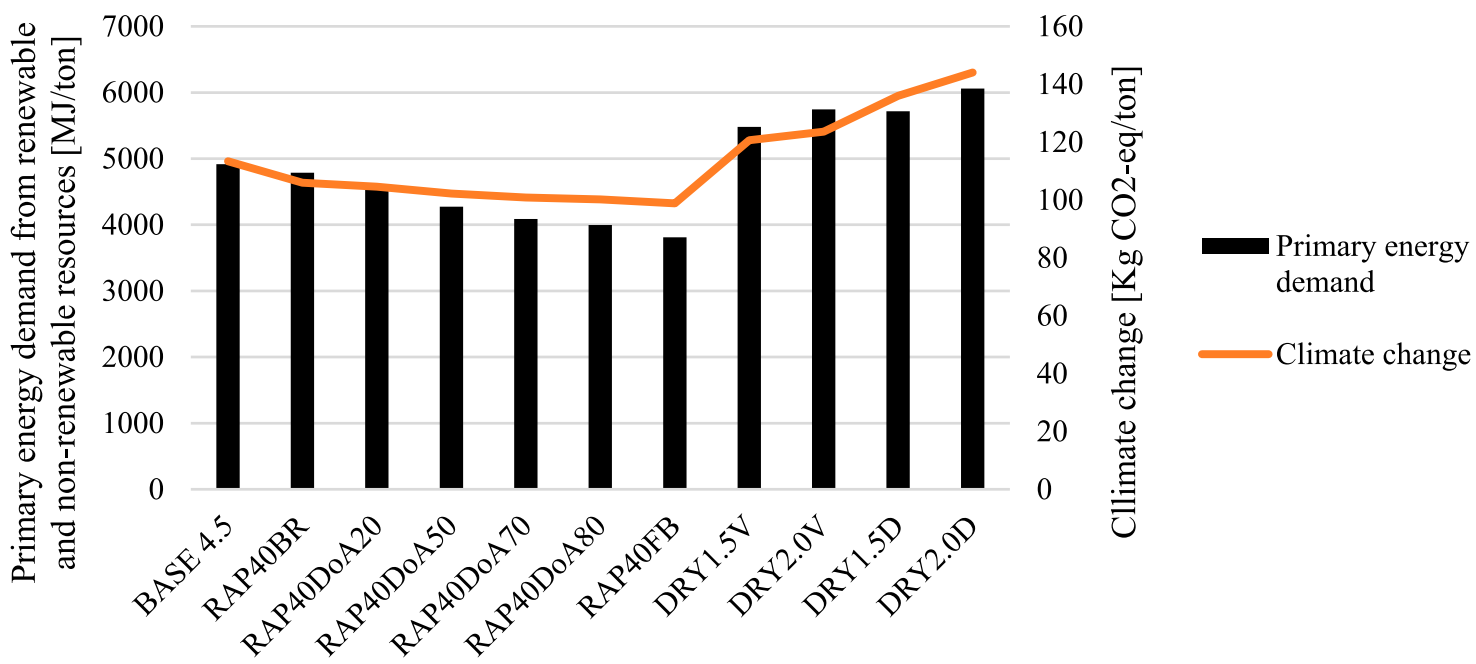

Figure 7. Primary energy demand and climate change derived from the production of asphalt mixtures containing CR and RAP in relation to those of the traditional asphalt mixture.

- Without an increase in the durability, the use of CR in asphalt mixtures leads to an increase of the scores in all impact categories. For the CR mixtures, the amount of bitumen increases as the amount of rubber in the mixture increases. That is due to the fact that rubber absorbs the lighter parts of the bitumen in the so-called 'maceration' process. The highest impact category scores are more pronounced in the case of devulcanised rubber because additional chemical treatments are required.

- Due to the rubber elasticity, the rubberised asphalt usually recovers deformation after the compaction phase. Therefore, by using a standard re-use of CR in asphalt mixtures, the percentage of rubber in CR mixtures cannot be increased significantly. As such, the small amount of CR used in this application does not justify all the additional consumption of resources and emissions associated with its treatment.

- Mixtures containing $40 \%$ of RAP reduce the scores of all the impact categories.

- Further reductions of all the resources consumed and emissions released can be achieved if the aged binder was fully reactivated and considered as $\mathrm{VB}$, thereby leading to a reduction of the amount of $\mathrm{VB}$ needed to be employed in a new mixture.

- The potential environmental benefits associated with all impact categories increase linearly when the DoA increases. The impact categories that showed the highest benefits when DoA increases are marine ecotoxicity, fossil depletion and human toxicity.

- It is recommended to develop additives able to reactivate the aged binder trapped in RAP, provided that the environmental impacts of their production, transportation and use do not offset the benefits obtained with the reduction of the use of VB.

To sum up, this study evaluated the environmental consequences of implementing innovative asphalt mixtures containing different percentages of recycled materials. The results show the negative effect deriving from the use of CR in the RUMAC technology. Nevertheless, certain potential benefits associated with the use of this technology were not considered, such as the reduction of noise and vibration. Therefore, the next steps of this research work will evaluate the sustainability of those materials by using a holistic and integrated approach that considers the three pillars of sustainability (environmental, social and economic).

Moreover, this research work opens the way to extend the study to other materials, such as, for instance, the assessment of the possible benefits derived from the use of rejuvenators (industrial or natural) when high RAP contents are used.

Finally, the availability of data to be used in the assessment of the environmental performance of these types of materials is still very limited. Therefore, further research efforts should be employed to produce a more complete and robust LCI that will certainly improve the overall quality of the LCA.

\section{Disclaimer}

The contents of this paper reflect the views of the authors, who are responsible for the facts and the accuracy of the data presented. The contents do not necessarily reflect the official views or policies of National Authorities. Any inclusion of manufacturer names, trade names or trademarks is for identification purposes only and is not to be considered an endorsement. Moreover, this paper does not constitute a standard, specification or regulation.

\section{Acknowledgements}

The third author is supported by the Ministry of Education, Science and Technological Development of the Republic of Serbia through the research project TR 36017 "Utilization of by-products and recycled waste materials in concrete composites in the scope of sustainable construction development in Serbia: investigation and environmental assessment of possible applications" and this support is gratefully acknowledged.

\section{Disclosure statement}

No potential conflict of interest was reported by the authors. 


\section{ORCID}

Marko Orešković (D) http://orcid.org/0000-0001-8978-0354

\section{References}

Airey, G.D., Rahman, M.M., and Collop, A.C, 2003. Absorption of bitumen into crumb rubber using the basket drainage method. International Journal of Pavement Engineering, 4 (2), 105-119.

Athena Institute, 2006. A life cycle perspective on concrete and asphalt roadways: embodied primary energy and global warming potential. Ottawa: Cement Association of Canada.

Autostrade-per-l'Italia, 2011. Sustainability report: estimate of emissions and $\mathrm{CO}_{2}$ savings derived from the adoption of in situ pavement recycling activities (in Italian).

Azarijafari, H., Yahia, A., and Ben Amor, M, 2016. Life cycle assessment of pavements: reviewing research challenges and opportunities. Journal of Cleaner Production, 112, 2187-2197.

Bressi, S., et al., 2018b. A comparative life-cycle assessment of asphalt mixtures for railway sub-ballast containing alternative materials. Resource, Conservation and Recycling, 137, 76-88.

Bressi, S., Colinas-Armijo, N., and Di Mino, G., 2018a. Analytical approach for the mix design optimisation of bituminous mixtures with crumb rubber. Materials and Structures, 51 (1), 26.

Bressi, S., Dumont, A.G., and Partl, M.N, 2016. A new laboratory methodology for optimization of mixture design of asphalt concrete containing reclaimed asphalt pavement material. Materials and Structures, 49 (12), 4975-4990.

CalRecovery, Inc., 2004. Evaluation of waste tire devulcanization technologies. Sacramento, CA: California Environmental Protection Agency.

Cao, W, 2007. Study on properties of recycled tire rubber modified asphalt mixtures using dry process. Construction and Building Materials, 21, 1011-1015.

Castorena, C., Pape, S., and Mooney, C, 2016. Blending Measurements in mixtures with reclaimed asphalt. Transportation Research Record: Journal of the Transportation Research Board, 2574, 57-63.

Cavalli, M.C., et al., 2016. Multiscale imaging and characterization of the effect of mixing temperature on asphalt concrete containing recycled components. Journal of Microscopy, 264 (1), 22-33.

Coffey, S., et al., 2013. Determining the impact of degree of blending and quality of reclaimed asphalt pavement on predicted pavement performance using pavement ME design. Construction and Building Materials, $48,473-478$

Dong, D., et al., 2012. Swelling process of rubber in asphalt and its effect on the structure and properties of rubber and asphalt. Construction and Building Materials, 29, 316-322.

EAPA, 2016. Guidance document for preparing Product Category Rules (PCR) and Environmental Product Declarations (EPD) for Asphalt Mixtures by the European Asphalt Association. 2016.

Ecopneus, 2013. Evaluation of the carbon footprint of the production of crumb rubber from end-of-life tires (in Italian). Milan: Ecopneus.

Ekvall, T. and Tillman, A.M, 1997. Open-loop recycling: criteria for allocation procedures. The International Journal of Life Cycle Assessment, 2, 155-162.

Estakhri, C., Button, J., and Fernando, E, 1992. Use, availability and cost effectiveness of asphalt rubber in Texas. Transportation Research Record, 1339, 30-37.

European Commission - Joint Research Centre - Institute for Environment and Sustainability, 2010. International Reference Life Cycle Data System (ILCD) handbook - General guide for life cycle assessment - Detailed guidance. Constraints.

Farina, A., et al., 2017. Life cycle assessment applied to bituminous mixtures containing recycled materials: Crumb rubber and reclaimed asphalt pavement. Resources, Conservation and Recycling, 117, 204212.

FHWA, 1997. User guidelines for waste and byproduct materials in pavement construction [online]. Report FHWA-RD-97-148. Available from: https://www.fhwa.gov/publications/research/infrastructure/ pavements/97148/index.cfm [Accessed 20 August 2003].
Fukumori, K., and Matsushita, M, 2003. Material recycling technology of crosslinked rubber waste. R\&D Review of Toyota CRDL, 38 (1), 39-47.

GaBi ts, 2017. Databases 2017 Edition, 2017.

Goedkoop, M., et al., 2013. Recipe 2008: A life cycle impact assessment method which comprises harmonised category indicators at the midpoint and the endpoint level. First edition (version 1.08). Report I: Characterisation.

Han, L., Zheng, M., and Wang, C, 2016. Current status and development of terminal blend tyre rubber modified asphalt. Construction and Building Materials, 128, 399-409.

Harvey J., et al., 2016. Pavement Life Cycle Assessment Framework. FHWA-HIF-16-014.

Hernandez-Olivares, F., et al., 2009. Rubber-modified hot-mix asphalt pavement by dry process. International Journal of Pavement Engineering, 10 (4), 277-288.

Hertwich, E, 2014. Understanding the climate mitigation benefits of product systems: comment on "using attributional life cycle assessment to estimate climate-change Mitigation...". Journal of Industrial Ecology, 18 (3), 464-465.

Huang, B., Zhang, Z., Kingery, W., and Zuo, G., 2004. Fatigue crack characteristics of HMA mixtures containing RAP. In: C. Petit, I. Al-Qadi and A. Millien, eds. Fifth international RILEM conference on reflective cracking in pavements. RILEM Publications SARL, 631-638.

ISO 14040, 2006. ISO 14040:2006 - environmental management - life cycle assessment - principles and framework. Geneve.

ISO 14044, 2006. ISO 14044:2006 - environmental management - life cycle assessment - requirements and guidelines. Geneve.

Jullien, A., et al., 2006. Air emissions from pavement layers composed of varying rates of reclaimed asphalt. Resources, Conservation and Recycling, 47 (4), 356-374.

Li, W., et al., 2014. A life cycle assessment case study of ground rubber production from scrap tires. International Journal of Life Cycle Assessment, 19 (11), 1833-1842.

Lo Presti, D., et al., 2019. On the degree of binder activity of reclaimed asphalt and degree of blending with recycling agents. Road Materials and Pavement Design, doi:10.1080/14680629.2019. 1607537.

Mangili, I, 2015. Mechanical and rheological properties of natural rubber compounds containing devulcanized ground tire rubber from several methods. Polymer Degradation and Stability, 121, 369-377.

Matthews, H.S., Hendrickson, C.T., and Matthews, D.H., 2015. Life cycle assessment: Quantitative approaches for decisions that matter. http:// www.lcatextbook.com.

McDaniel, R.S., et al., 2000. Recommended use of reclaimed asphalt pavement in the superpave mix design method. NCHRP Web document 30 (project D9-12). Washington, DC: Transportation Reserach Board of National Academics.

National Asphalt Pavement Association (NAPA), 2017. Product Category Rules (PCR) For Asphalt Mixtures.

The Norwegian EPD Foundation, 2010. Product-Category Rules (PCR) for preparing an Environmental Product Declaration (EPD) for Product Group Asphalt and crushed stone, (November), 1-22.

Porot, L., et al., 2016. Life cycle evaluation for reusing Reclaimed Asphalt with a bio-rejuvenating agent. Proceedings of 6th Eurasphalt \& Eurobitume Congress, 1st-3rd June 2016, June, 1-8.

Rader, C., et al., 1995. Plastics, rubber, and paper recycling. A pragmatic approach. American Chemical Society.

Rafique, R.M.U, 2012. Life cycle assessment of waste car tyres at Scandinavian enviro systems. Göteborg: Chalmers University of Technology.

Rajan, V. V., et al., 2006. Science and technology of rubber reclamation with special attention to NR-based waste latex products. Progress in Polymer Science (Oxford, 31 (9), 811-834.

Ruban, A, 2012. Life cycle assessment of plastic Bag production. Uppsala: Uppsala University.

Santagata, E., et al., 2016. Analysis of bitumen-crumb rubber affinity for the formulation of rubberized dry mixtures. Materials and Structures, 49, 1947-1954. 
Santero, N.J., Masanet, E., and Horvath, A, 2011a. Life-cycle assessment of pavements. part I: Critical review. Resources, Conservation and Recycling, 55 (9-10), 801-809.

Santero, N.J., Masanet, E., and Horvath, A, 2011b. Life-cycle assessment of pavements. part II: Filling the research gaps. Resources, Conservation and Recycling, 55 (9-10), 801-809.

Santos, J., et al., 2019. SUP\&r DSS: A sustainability-based decision support system for road pavements. Journal of Cleaner Production, 206, 524-540.

Santos, J., Ferreira, A., and Flintsch, G, 2015. A life cycle assessment model for pavement management: road pavement construction and management in Portugal. International Journal of Pavement Engineering, 16 (4), 315-336.

Schrijvers, D.L., Loubet, P., and Sonnemann, G, 2016. Critical review of guidelines against a systematic framework with regard to consistency on allocation procedures for recycling in LCA. International Journal of Life Cycle Assessment, 21 (7), 994-1008.

Shirodkar, P., et al., 2011. A study to determine the degree of partial blending of reclaimed asphalt pavement (RAP) binder for high RAP hot mix asphalt. Construction and Building Materials, 25 (1), 150-155.
Silva, H.M.R.D., Oliveira, J.R.M., and Jesus, C.M.G, 2012. Are totally recycled hot mix asphalts a sustainable alternative for road paving? Resources, Conservation and Recycling, 60, 38-48.

Turgeon, C.M., 1989. The use of asphalt-rubber products in Minnesota. In: National seminar on asphalt-rubber. Kansas City, MO.

Wang, T., et al., 2018. Energy consumption and environmental impact of rubberized asphalt pavement. Journal of Cleaner Production, 180, 139158. doi:10.1016/j.jclepro.2018.01.086.

White, P, et al., 2010. Modeling climate change impacts of pavement production and construction. Resources, Conservation and Recycling, 54, 776-782.

Yang, R, 2014. Development of a pavement life cycle assessment tool utilizing regional data and introducing an asphalt binder model. University of Illinois at Urbana-Champaign.

Zapata, P, and Gambatese, JA, 2005. Energy consumption of asphalt and reinforced concrete pavement materials and construction. Journal Infrastructure System, 11, 9-20.

Zaumanis, M., et al., 2012. Calculation of asphalt production energy flow to compare warm and hot mix asphalt. In: Proceedings of 5th Eurasphalt \& Eurobitume Congress. Istanbul: EAPA, 216-225. 